Article

\title{
Targeted Mutagenesis of the Rice FW 2.2-Like Gene Family Using the CRISPR/Cas9 System Reveals OsFWL4 as a Regulator of Tiller Number and Plant Yield in Rice
}

\author{
Qingsong Gao ${ }^{1,+}$, Gang Li ${ }^{2,+}$, Hui Sun ${ }^{1}$, Ming Xu ${ }^{1}$, Huanhuan Wang ${ }^{1}$, Jianhui Ji ${ }^{1}$, Di Wang ${ }^{2}$, \\ Caiyong Yuan ${ }^{2, *}$ and Xiangxiang Zhao ${ }^{1, *}$ \\ 1 Jiangsu Collaborative Innovation Center of Regional Modern Agriculture \& Environmental \\ Protection/Jiangsu Key Laboratory for Eco-Agricultural Biotechnology around Hongze Lake, Huaiyin \\ Normal University, Huai'an 223300, China \\ 2 Huaiyin Institute of Agricultural Sciences of Xuhuai Region in Jiangsu, Huai'an 223001, China \\ * Correspondence: hysdycy@163.com (C.Y.); xxzhao2013@163.com (X.Z.); Tel.: +86-517-83659907 (C.Y.); \\ $+86-517-83525885$ (X.Z.) \\ + These authors contributed equally to this work.
}

Received: 30 November 2019; Accepted: 22 January 2020; Published: 26 January 2020

\begin{abstract}
The $F W 2.2-$ like $(F W L)$ genes encode cysteine-rich proteins with a placenta-specific 8 domain They play roles in cell division and organ size control, response to rhizobium infection, and metal ion homeostasis in plants. Here, we target eight rice FWL genes using the CRISPR/Cas9 system delivered by Agrobacterium-mediated transformation. We successfully generate transgenic $\mathrm{T}_{0}$ lines for 15 of the 16 targets. The targeted mutations are detected in the $\mathrm{T}_{0}$ lines of all 15 targets and the average mutation rate is found to be $81.6 \%$. Transfer DNA (T-DNA) truncation is a major reason for the failure of mutagenesis in $\mathrm{T}_{0}$ plants. T-DNA segregation analysis reveals that the T-DNA inserts in transgenic plants can be easily eliminated in the $\mathrm{T}_{1}$ generation. Of the 30 putative off-target sites examined, unintended mutations are detected in 13 sites. Phenotypic analysis reveals that tiller number and plant yield of OsFWL4 gene mutants are significantly greater than those of the wild type. Flag leaves of OsFWL4 gene mutants are wider than those of the wild type. The increase in leaf width of the mutants is caused by an increase in cell number. Additionally, grain length of OsFWL1 gene mutants is higher than that of the wild type. Our results suggest that transgene-free rice plants with targeted mutations can be produced in the $\mathrm{T}_{1}$ generation using the Agrobacterium-mediated CRISPR/Cas9 system and that the OsFWL4 gene is a negative regulator of tiller number and plant yield.
\end{abstract}

Keywords: FW2.2-like gene; tiller number; grain yield; rice; CRISPR/Cas9; genome editing; off-target effect

\section{Introduction}

$f w 2.2$ is a major quantitative trait locus that regulates fruit size and weight in tomato [1,2]. The underlying gene FW2.2 regulates fruit size by negatively regulating cell division [2,3]. Homolog identification and sequence analysis have revealed that FW2.2 belongs to a large eukaryotic family of cysteine-rich proteins containing a featured placenta-specific 8 domain $[4,5]$. FW2.2-like $(F W L)$ genes have been characterized in various plant species and are reported to play important roles in diverse biological processes, such as cell number and organ size control [4,6-9], nodulation [5,10], and metal ion homeostasis [11-20]. The rice FWL gene family contains eight members [9]. Among them, the OsFWL3 gene is reported to negatively affect grain length and weight by regulating cell division in 
the glume [9]. However, the OsFWL4 gene has been reported to affect cadmium (Cd) resistance upon expression in yeast [15]. RNA interference-mediated knockdown of OsFWL4 has been found to reduce translocation of $\mathrm{Cd}$ from the roots to shoots in rice seedlings. More recently, a change in the expression of OsFWL1 and OsFWL2 induced by their overexpression or RNA interference has been found to affect $\mathrm{Cd}$ tolerance and accumulation in rice [20]. Interestingly, the OsFWL5/PCR1 gene, which affects Cd and $\mathrm{Zn}$ tolerance when expressed in yeast cells, has been reported to regulate metal ion homeostasis and grain size and weight in rice $[13,14]$. However, whether other Cd-responsive rice $F W L$ genes also play a role in plant and organ development in rice remains unknown.

Generating mutants with intended mutations is crucial for functional analysis of plant genes. The clustered regularly interspaced short palindromic repeats (CRISPR)/CRISPR-associated protein 9 (Cas9) system is a powerful tool for genome editing in various organisms, including plants. This system induces DNA double-strand breaks at given genomic sites, which are subsequently repaired by either non-homologous end joining or homologous recombination pathways in the cells [21]. Non-homologous end joining is error-prone and can act throughout the cell cycle. It is therefore commonly utilized to disrupt genes by creating random insertions or deletions (indels) at target sites [22]. In the presence of a homologous DNA template, a double-strand break can be repaired by homologous recombination, leading to target gene replacement or insertion. The precise cleavage of the target DNA using the CRISPR/Cas9 system requires two components, namely, Cas9 nuclease harboring $\mathrm{HNH}$ and RuvC endonuclease domains for cleaving and an engineered single-guide RNA (sgRNA) for directing Cas9 to the target site [23]. A prerequisite for binding and cleavage of the target DNA is the presence of a trinucleotide protospacer adjacent motif (PAM) immediately after the target DNA [24]. Sequence specificity can be achieved by changing a 20-nucleotide "guide sequence" in the sgRNA. As this system does not require protein engineering, the nuclease can be easily reprogrammed. With the development of highly efficient CRISPR/Cas9 systems, stable homozygous mutants can be obtained within a single generation in many plants [25-28].

Agrobacterium-mediated transfer DNA (T-DNA) transformation is commonly used for delivering CRISPR/Cas9 DNA into rice cells. In this study, two target sites are designed for each of the eight rice FWL genes for gene editing using the Agrobacterium-mediated CRISPR/Cas9 system. We generate transgenic $\mathrm{T}_{0}$ lines from 15 out of 16 constructs and detect targeted mutations in all $\mathrm{T}_{0}$ lines. Gene editing efficiency, T-DNA segregation patterns, and off-target effects are analyzed. The phenotypes of homozygous and transgene-free mutants with no detected off-target mutations of the OsFWL1 and OsFWL4 genes are then examined. Our results suggest that OsFWL4 is a negative regulator of tiller number and plant yield in rice and that OsFWL1 plays a role in modulating rice grain length.

\section{Results}

\subsection{Generation of Rice FWL Gene Mutants Using CRISPR/Cas9}

Two target sites were designed in the coding region of each of the eight rice FWL genes for CRISPR/Cas9 gene editing (Table 1). The GC content in these target sites was in the range $45-75 \%$. The synthesized oligos were inserted into the CRISPR/Cas9 binary vector (Figure S1). Subsequently, the 16 constructed vectors were transformed into the Japonica rice variety Zhonghua 11 using the Agrobacterium-mediated method.

Of the 16 vectors, we successfully generated transgenic $\mathrm{T}_{0}$ lines for 15 vectors (Table 2 ). We detected targeted mutations in all those $\mathrm{T}_{0}$ lines. The mutation rates varied from $26.7 \%$ to $100 \%$, and the average mutation rate was $81.6 \%$ (Table 2), suggesting that the CRISPR/Cas9 system constructed in this study is efficient in rice gene editing. Bi-allelic mutants were detected in $\mathrm{T}_{0}$ plants from each vector, with detection percentages varying from $20.0 \%$ to $87.5 \%$ (Table 2). Homozygous mutants were detected in $\mathrm{T}_{0}$ plants from 13 vectors, with the highest detection percentage being $64.3 \%$. By contrast, heterozygotes and chimeras were detected only in $\mathrm{T}_{0}$ plants from three vectors (Table 2). 
The percentage of heterozygotes and chimeras in all $\mathrm{T}_{0}$ plants was only $1.3 \%$ and $4.0 \%$, respectively. Detailed sequencing results of all $\mathrm{T}_{0}$ mutants are shown in Table $\mathrm{S} 1$.

Table 1. Target sites of rice $F W L$ genes for clustered regularly interspaced short palindromic repeats (CRISPR)/CRISPR-associated protein 9 (Cas9)-mediated gene editing.

\begin{tabular}{|c|c|c|c|c|}
\hline Gene & Locus & Target Name & Target Sequence $\left(5^{\prime}-3^{\prime}\right)^{1}$ & GC Content ( $\%)$ \\
\hline \multirow[t]{2}{*}{ OsFWL1 } & LOC_Os02g52550 & Osfwl1a & CTGAAGGACTTACAGTTTCC GGG & 45 \\
\hline & & Osfwl1b & TGGGCAGGTCGCTGACATCG TGG & 65 \\
\hline \multirow[t]{2}{*}{ OsFWL2 } & LOC_Os02g36940 & Osfwl2a & GCGCTGGTGATGCTCCTCAC GGG & 65 \\
\hline & & Osfwl2b & CATCTTGGCGCGGTAGAAGC AGG & 60 \\
\hline \multirow[t]{2}{*}{ OsFWL3 } & LOC_Os02g36950 & Osfwl3a & ATCGCGGAGATCGTCGACCG GGG & 65 \\
\hline & & Osfwl3b & GTGGACGAGGCAGTCGGGGC AGG & 75 \\
\hline \multirow[t]{2}{*}{ OsFWL4 } & LOC_Os03g61440 & Osfwl4a & ATTGAAGCAGGCGAAGAGTC CGG & 50 \\
\hline & & Osfwl4b & CGCAGCATGGGTCCTCGGGG AGG & 75 \\
\hline \multirow[t]{2}{*}{ OsFWL5 } & LOC_Os10g02300 & Osfwl5a & ATCGCAGAAATCGTCGACAG GGG & 50 \\
\hline & & Osfwl5b & CTCACGGTGCATCTGTGCGA TGG & 60 \\
\hline \multirow[t]{2}{*}{ OsFWL6 } & LOC_Os03g61470 & Osfwl6a & TCGACGTCGTGCGGCACCGG CGG & 75 \\
\hline & & Osfwl6b & GGCAAGATGCGCACTCAGTA CGG & 55 \\
\hline \multirow[t]{2}{*}{ OsFWL7 } & LOC_Os03g61500 & Osfwl7a & CCCGTGCATCACGTTCGGGC GGG & 70 \\
\hline & & Osfwl7b & CATCTTGCCCCGGTAGACGC AGG & 65 \\
\hline \multirow[t]{2}{*}{ OsFWL8 } & LOC_Os03g61480 & Osfwl8a & GGGTCGACGTCGTTCGGCAC CGG & 70 \\
\hline & & Osfwl8b & GTTGAGGTGCCATCCGAGCT TGG & 60 \\
\hline
\end{tabular}

${ }^{1}$ The protospacer adjacent motif (PAM) sequences are shown in green.

Table 2. Identification of targeted mutations in $\mathrm{T}_{0}$ plants.

\begin{tabular}{|c|c|c|c|c|c|c|c|}
\hline \multirow{2}{*}{ Target } & \multirow{2}{*}{$\begin{array}{l}\text { No. of } T_{0} \text { Plants } \\
\text { Obtained }\end{array}$} & \multirow{2}{*}{$\begin{array}{l}\text { No. of Plants with } \\
\text { Mutations }\end{array}$} & \multicolumn{4}{|c|}{ Zygosity } & \multirow{2}{*}{$\begin{array}{c}\text { Combined Percentage of Homozygous } \\
\text { and Bi-Allelic Mutants (\%) }\end{array}$} \\
\hline & & & Homozygou & s Bi-Allelic & Heterozyg & sChimeric & \\
\hline Osfwl1a & 15 & $7(46.7 \%)$ & - & $7(46.7 \%)$ & - & - & 46.7 \\
\hline Osfwl1b & 14 & $14(100.0 \%)$ & $9(64.3 \%)$ & $5(35.7 \%)$ & - & - & 100.0 \\
\hline Osfwl2a & 16 & $15(93.8 \%)$ & $1(6.3 \%)$ & $14(87.5 \%)$ & - & - & 93.8 \\
\hline Osfwl2b & 14 & $11(78.6 \%)$ & $3(21.4 \%)$ & $8(57.1 \%)$ & - & - & 78.6 \\
\hline Osfwl3a & 7 & $6(85.7 \%)$ & - & $4(57.1 \%)$ & - & $2(28.6 \%)$ & 57.1 \\
\hline Osfwl3b & 25 & $22(88.0 \%)$ & $2(8.0 \%)$ & $13(52.0 \%)$ & $1(4.0 \%)$ & $6(24.0 \%)$ & 60.0 \\
\hline Osfwl4a & 15 & $11(73.3 \%)$ & $3(20.0 \%)$ & $8(53.3 \%)$ & - & - & 73.3 \\
\hline Osfwl4b & 15 & $10(66.7 \%)$ & $1(6.7 \%)$ & $8(53.3 \%)$ & - & $1(6.7 \%)$ & 60.0 \\
\hline Osfwl5a & 14 & $14(100.0 \%)$ & $2(14.3 \%)$ & $12(85.7 \%)$ & - & - & 100.0 \\
\hline Osfwl5b & 14 & $14(100.0 \%)$ & $7(50.0 \%)$ & $7(50.0 \%)$ & - & - & 100.0 \\
\hline Osfwl6a & 15 & $4(26.7 \%)$ & $1(6.7 \%)$ & $3(20.0 \%)$ & - & - & 26.7 \\
\hline Osfwl6b & 16 & $15(93.8 \%)$ & $5(31.3 \%)$ & $10(62.5 \%)$ & _- & - & 93.8 \\
\hline Osfwl7a & 14 & $13(92.9 \%)$ & $2(14.3 \%)$ & 10 (71.4\%) & $1(7.1 \%)$ & - & 85.7 \\
\hline Osfwl7b & 15 & $12(80.0 \%)$ & $5(33.3 \%)$ & $6(40.0 \%)$ & $1(6.7 \%)$ & - & 73.3 \\
\hline Osfwl8b & 14 & $14(100.0 \%)$ & $3(21.4 \%)$ & $11(78.6 \%)$ & - & - & 100.0 \\
\hline Total & 223 & $182(81.6 \%)$ & $44(19.7 \%)$ & $\begin{array}{c}126 \\
(56.5 \%)\end{array}$ & $3(1.3 \%)$ & $9(4.0 \%)$ & 76.2 \\
\hline
\end{tabular}

Sequencing analyses revealed that most mutations were short indels; $62.3 \%$ of indels were $1 \mathrm{bp}$ changes (Figure 1A,B). A majority of the $1 \mathrm{bp}$ insertions (83.2\%) were either A or T, which is consistent with previous reports $[27,29]$.

Of the $223 \mathrm{~T}_{0}$ plants, 41 plants did not contain mutations. To test whether failed editing of these plants was caused by a lack of the CRISPR/Cas9 construct, the presence of hygromycin phosphotransferase (HPT), sgRNA, and Cas9 transgenes in these 41 plants was examined. Two plants did not contain HPT, sgRNA, and Cas9 sequences (Table S2), which suggests that these plants escaped hygromycin selection. Twenty-five plants did not contain sgRNA and/or Cas9 sequences (Table S2) which suggests that incompleteness of the sgRNA/Cas 9 expression cassette led to failed mutagenesis in these plants. Interestingly, when unmutated $\mathrm{T}_{0}$ plants without the complete sgRNA/Cas 9 construct were excluded, all targets except Osfwl1a, Osfwl4a, and Osfwl6a had a mutation rate of 100\% (Table 2 and Table S2). The score of sgRNA activity in all targets predicted using the sgRNA Scorer 2.0 varied from -0.64 to 1.09 (Table S3), indicating moderate efficiency of the sgRNAs [30]. 

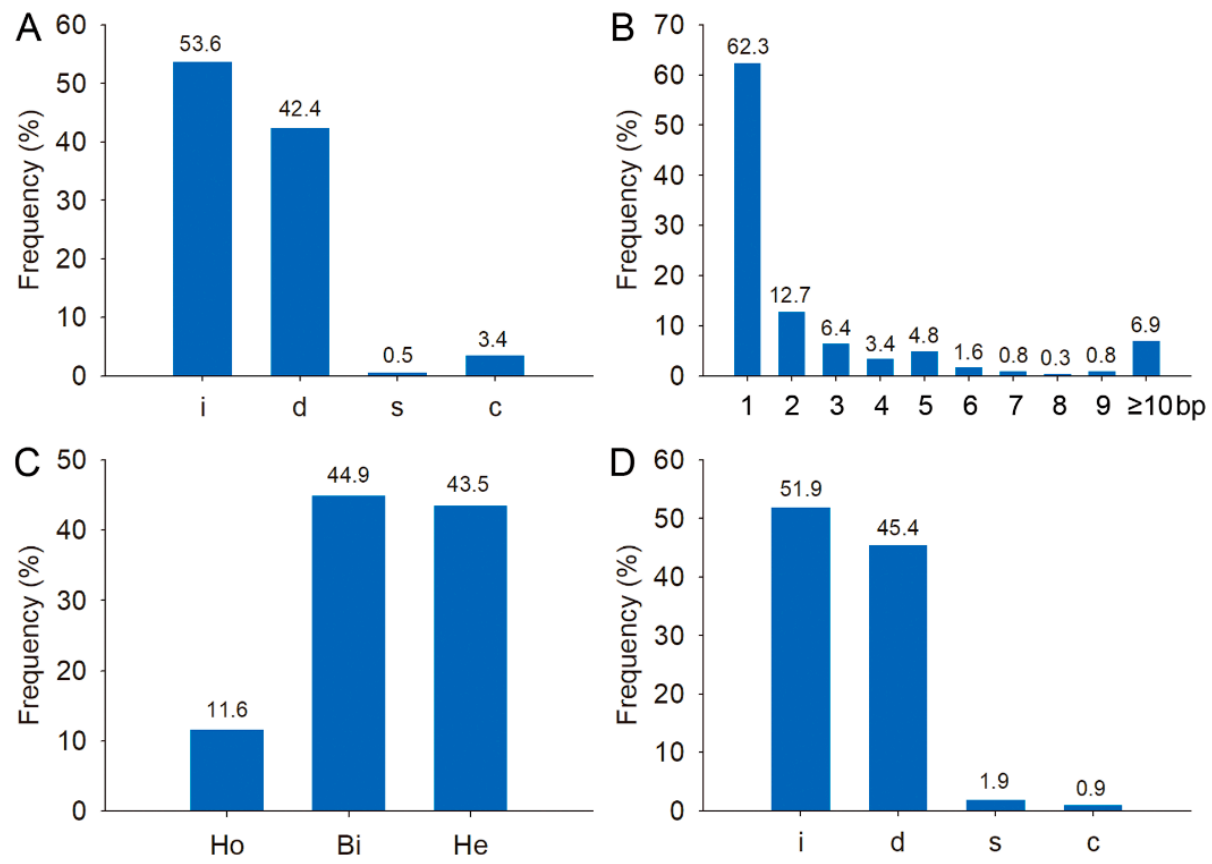

Figure 1. Characterization of on-target and off-target mutations. (A) Frequencies of different types of on-target mutations. (B) Frequencies of different lengths of on-target mutations. (C) Zygosity of off-target mutations. (D) Types of off-target mutations. Legend: i, insertion; d, deletion; s, substitution; c, combined mutation; Ho, homozygote; Bi, bi-allele; He, heterozygote.

The inheritance patterns of targeted mutations in later generations were also examined. Mutations of most homozygous $T_{0}$ plants were stably transmitted to the $T_{1}$ generation (Table S4). However, unexpected genotypes were detected in the $\mathrm{T}_{1}$ generation of four of the five bi-allelic $\mathrm{T}_{0}$ plants. Additionally, a large proportion of the progeny of a chimeric $\mathrm{T}_{0}$ plant were chimeras (Tables $\mathrm{S} 4$ and S5). The transmission of mutations of several randomly selected $\mathrm{T}_{1}$ lines that did not contain transgenes ('transgene-free'; see Section 2.2) in the $T_{2}$ generation was also examined. The genotypes of all these lines were faithfully transmitted to $\mathrm{T}_{2}$ plants (Table $\mathrm{S} 6$ ).

\subsection{Segregation of $T$-DNA in the $T_{1}$ Generation}

The presence of CRISPR/Cas9 DNA and marker genes in gene-edited plants may cause adverse effects, such as an increased risk of off-target changes, and may trigger regulation concerns when these plants are used in crop breeding [22,31,32]. To test whether the T-DNA fragment carrying the CRISPR/Cas9 construct could be segregated out in the progeny of $\mathrm{T}_{0}$ mutants, the presence of HPT, sgRNA, and Cas 9 transgenes in $\mathrm{T}_{1}$ plants derived from one of the homozygous or bi-allelic $\mathrm{T}_{0}$ mutants of each target (except Osfwl3a) was examined (Figure S2). For target Osfwl3a, the progeny of a chimeric $\mathrm{T}_{0}$ plant (Osfwl3a\#4) were used. The genotype of the $\mathrm{T}_{0}$ mutant for each $\mathrm{T}_{1}$ line used is shown in Table S1. Transgene-free plants were obtained in several randomly selected $\mathrm{T}_{1}$ progeny for all lines (Figure S2), suggesting that the number of T-DNA insertion loci was low in $\mathrm{T}_{0}$ plants.

In most $T_{1}$ lines (13 out of 15 ) analyzed, consistent segregation patterns were observed for all the HPT, sgRNA, and Cas9 transgenes (Figure S2). However, inconsistent segregation patterns were detected in two lines (Osfwl3a\#4 and Osfwl4b\#6). In line Osfwl3a\#4, HPT and Cas9 sequences were not detected in some plants, although the sgRNA sequence was present (Figure S2). Interestingly, the eight $\mathrm{T}_{1}$ plants of this line that lacked the complete sgRNA/Cas 9 expression cassette were all homozygotes, whereas the other 12 plants containing the complete sgRNA/Cas 9 expression cassette were all chimeras (Figures S2 and S3; Tables S4 and S5). In line Osfwl4b\#6, sgRNA and Cas9 sequences were not detected in all examined $\mathrm{T}_{1}$ plants, but the HPT sequence was present in some of the plants (Figure S2). Next, we 
examined the $\mathrm{T}_{0}$ plant of this line for the presence of a T-DNA fragment and found that it also lacked sgRNA and Cas9 sequences. This indicates that mutations of this line were generated by transient CRISPR/Cas9 expression.

\subsection{Phenotypic Analysis of Rice FWL Gene Mutants}

Phenotypes of allelic mutant lines that were homozygous, transgene-free, and with no detected off-target effects (see Section 2.4) of the OsFWL1 and OsFWL4 genes were analyzed. For OsFWL1, $\mathrm{T}_{2}$ plants of lines Osfwl1a\#4 and Osfwl1b\#11 (Table S6) were selected for Osfwl1a and Osfwl1b targets, respectively. For OsFWL4, $\mathrm{T}_{3}$ plants of lines Osfwl4a\#7 and Osfwl4b\#6 (Table S6) were analyzed for Osfwl4a and Osfwl4b targets, respectively.

The number of tillers per osfwl $4 a$ and osfwl $4 b$ mutant plants was $45.9 \%$ and $41.1 \%$ greater, respectively, than that of the wild type (WT; Figure 2A,B). The number of grains per panicle of mutants was not significantly changed (Figure 2C). Although 1000-grain weight of mutants was slightly reduced (Figure 2D), the grain yield per plant was increased by 25.6-35.8\% (Figure 2E).

Additionally, the flag leaf width of osfwl $4 a$ and osfwl $4 b$ mutants was $7.7 \%$ and $6.3 \%$ greater, respectively, than that of the WT (Figure 3A,C). However, there was no marked difference in flag leaf length (Figure 3B). Analysis of leaf epidermal cell size revealed no significant difference in cell length and width between WT and mutants (Figure S4). This suggests that the increase in leaf width of mutants was caused by an increase in cell number but not in cell size. In addition, the plant height of mutants was slightly reduced compared with that of the WT (Figure 2A and Figure S5).

The expression profile of the OsFWL4 gene during the life cycle of rice was examined using qRT-PCR. OsFWL4 was mainly expressed in the developing endosperm and the stem at the heading stage (Figure 4); it was also expressed in the leaf, root, and panicle. To gain insights into the molecular function of OsFWL4, a gene co-expression analysis was performed using the Genevestigator program [33] with the mRNA-Seq datasets. Many positively correlated genes of OsFWL4 were involved in cell signal transduction, disease resistance, and heavy metal resistance (Table S7). Interestingly, some negatively correlated genes of OsFWL4 were found to encode the F-box domain- and BTB (bric-a-brac, tramtrack and broad complex) domain-containing proteins, which may play a role in protein ubiquitination [34] (Table S8).

Grain length of osfwl1 $a$ and osfwl $1 b$ mutants was $4.2 \%$ and $5.5 \%$ greater, respectively, than that of the WT (Figure 5A,B). However, there was no difference in grain width between the mutants and WT plants (Figure 5C). Grain thickness of mutants was slightly lower than that of the WT (Figure 5D). Finally, there was no change in the 1000-grain weight of mutants (Figure 5E). Additionally, plant height, leaf size, and grain yield per plant of mutants were not considerably different from those of the WT (Figure S6). 

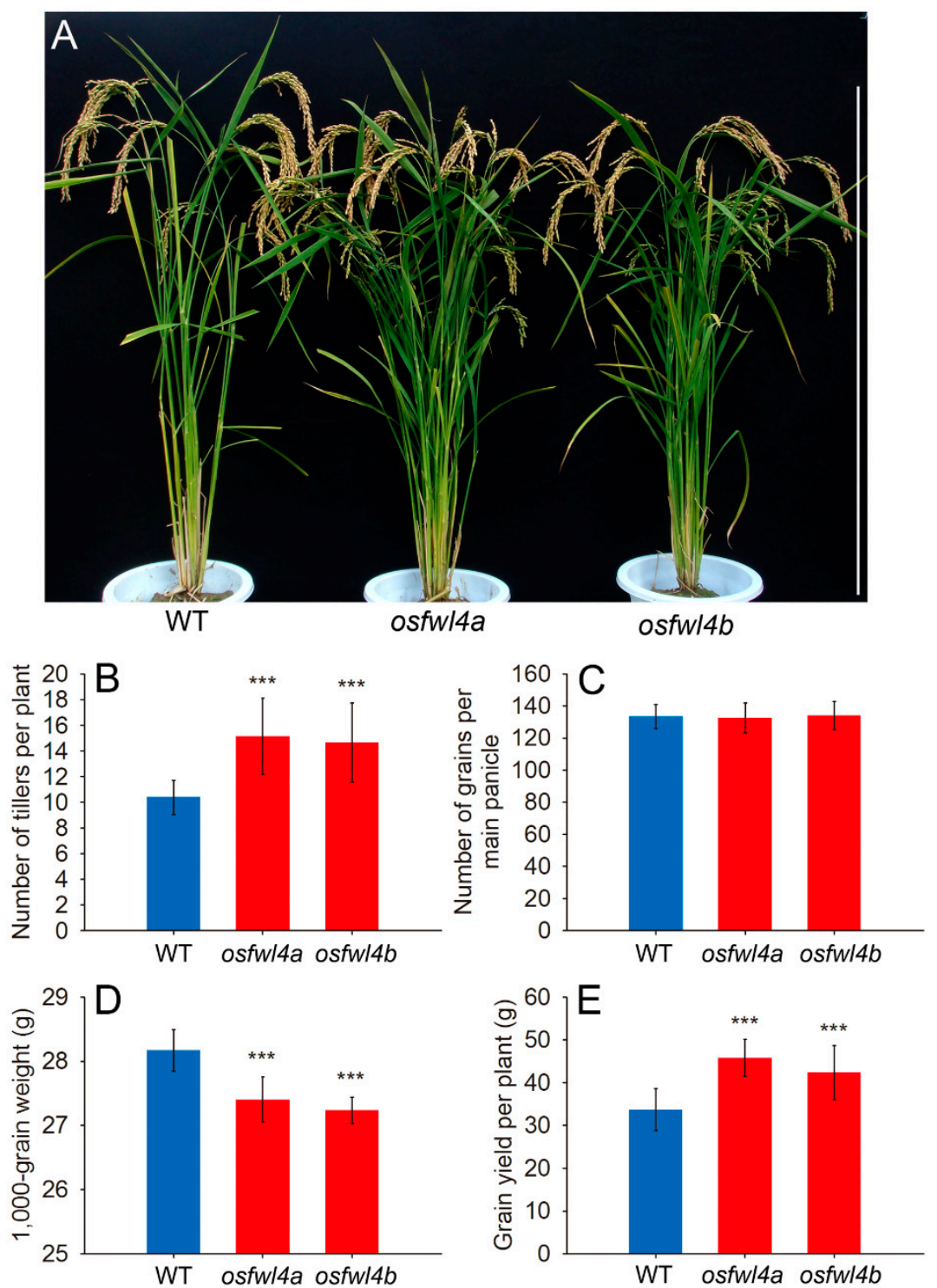

Figure 2. Analysis of yield traits of wild type (WT) and OsFWL4 gene mutants. (A) WT and mutant plants, bar $=1 \mathrm{~m}$. (B) Number of tillers per plant of the WT and mutants, $n=20$. (C) Number of grains per main panicle of the WT and mutants, $n=10$. (D) 1000-grain weight of the WT and mutants, $n=10$. (E) Grain yield per plant of the WT and mutants, $n=12-15$. Error bars are standard deviations. $* * * p<0.001$. 

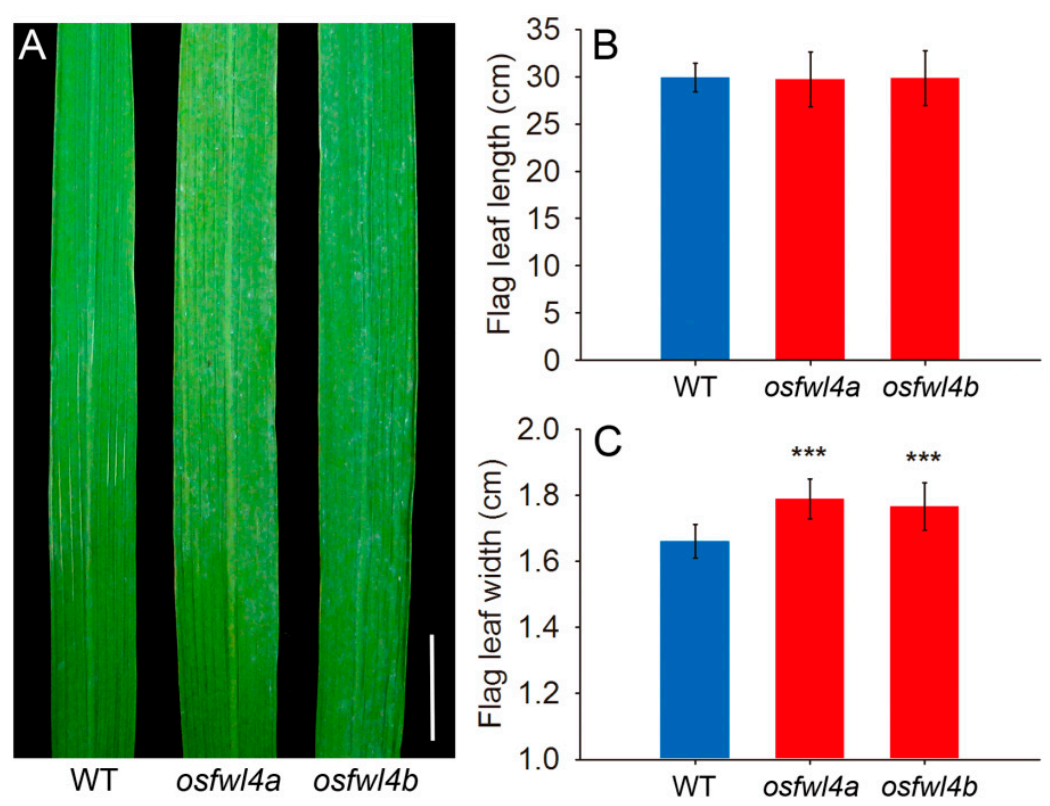

Figure 3. Phenotypes of flag leaves of WT and OsFWL4 gene mutants. (A) Flag leaves of the WT and mutants, bar $=2 \mathrm{~cm}$. (B) Flag leaf length of the WT and mutants. (C) Flag leaf width of the WT and mutants. The values in (B) and (C) are means of 20 plants. Error bars are standard deviations. ${ }^{* * *} p<0.001$.

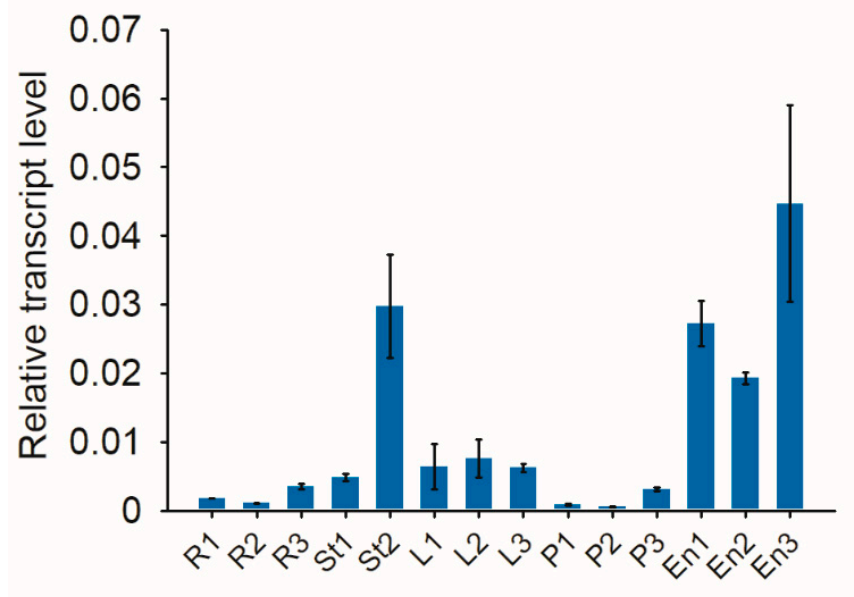

Figure 4. qRT-PCR results of the OsFWL4 gene in 14 tissue samples of japonica rice Zhonghua 11. The rice Actin1 gene was used as the internal control. Legend: R1-R3, roots in the seedling, tillering, and heading stages, respectively; St1 and St2, stems in the jointing and heading stages, respectively; L1-L3, leaves in the seedling, tillering, and heading stages, respectively; P1-P3, panicles 5, 15, and $20 \mathrm{~cm}$ in length, respectively; En1-En3, endosperms 5, 14, and 21 days after pollination. Error bars are standard deviations of three technical repeats. 

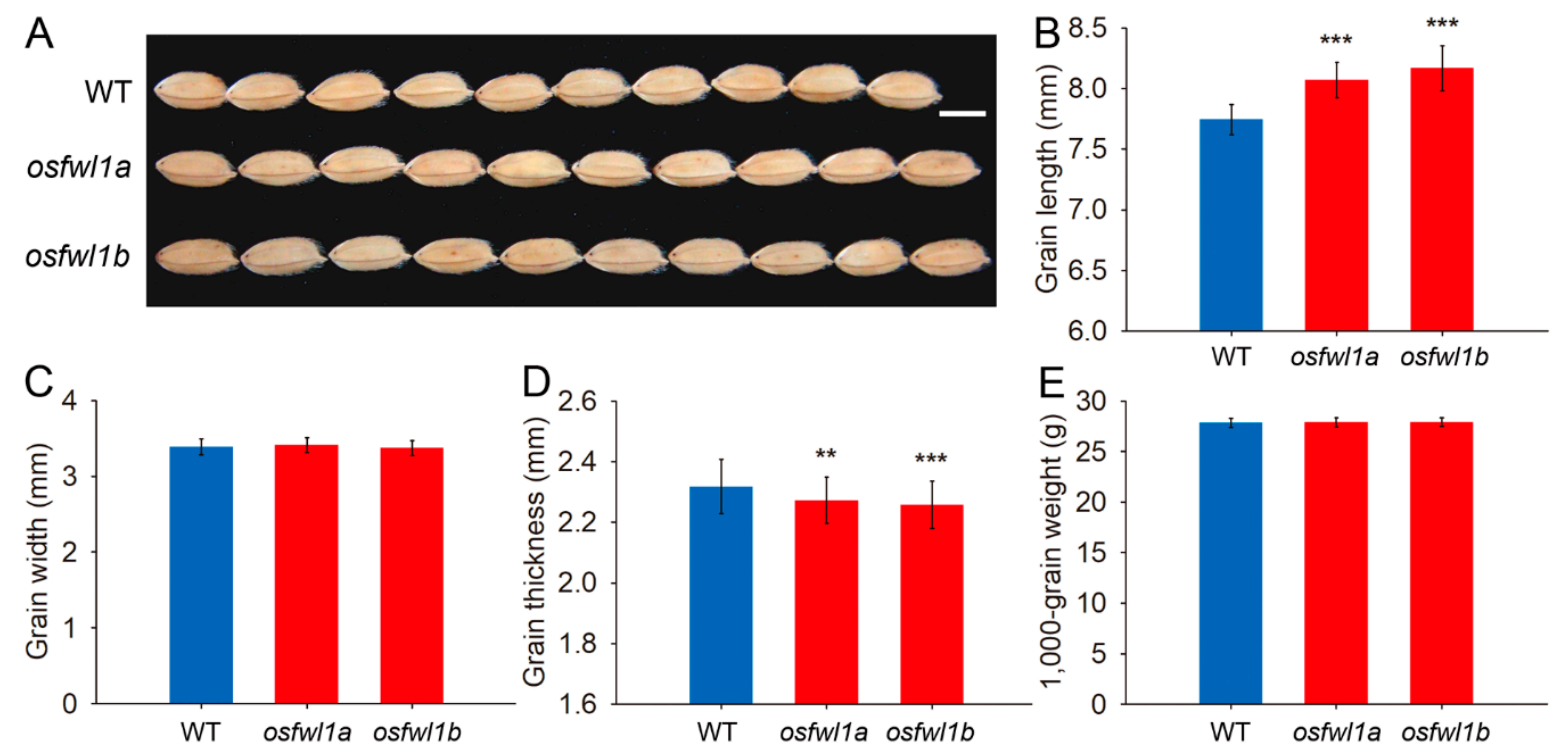

Figure 5. Analysis of grain shape of WT and OsFWL1 gene mutants. (A) Grains of the WT and mutants, bar $=5 \mathrm{~mm}$. (B) Grain length of the WT and mutants, $n=50$. (C) Grain width of the WT and mutants, $n=50$. (D) Grain thickness of the WT and mutants, $n=50$. (E) 1000-grain weight of the WT and mutants, $n=10$. Error bars are standard deviations. ${ }^{* *} p<0.01 ;{ }^{* * *} p<0.001$.

\subsection{Analysis of Off-Target Effects}

To investigate the potential off-target events in our experiments, the two most probable off-target sites were selected for each of the 15 targets. The potential editing events in these sites were examined in all $\mathrm{T}_{0}$ plants and several randomly selected $\mathrm{T}_{1}$ lines. When the same off-target sequence occurred at different genomic loci, only one locus was examined. Of the 30 putative off-target sites, we detected mutations in 13 sites (Table 3). All the five loci that had a single-base mismatch with sgRNA exhibited off-target effects. Mutations were detected in four of the five $(80.0 \%)$ and three of the $10(30.0 \%)$ loci that had two and three mismatches, respectively. Additionally, one locus (Osfwl2aOFF-2) that had four dispersed mismatches was cleaved in transgenic plants. No mutations were detected in the loci that had five mismatches with sgRNA (Table 3). Most of the off-target sites with mutations were located within the gene region (Table 3). 
Table 3. Off-target effect analysis of transgenic plants.

\begin{tabular}{|c|c|c|c|c|c|c|}
\hline $\begin{array}{l}\text { Name of Putative } \\
\text { Off-Target Site }\end{array}$ & Locus & Sequence of Putative Off-Target Site ${ }^{1}$ & Region & $\begin{array}{c}\text { No. of Mismatching } \\
\text { Bases }\end{array}$ & No. of Plants Tested & $\begin{array}{l}\text { No. of Plants with } \\
\text { Mutations }\end{array}$ \\
\hline Osfwl1aOFF-1 & Chr2: 11000661-11000683 & CTGAATGACTGACTGTCTCC TGG & LOC_Os02g18850 intron & 4 & 32 & 0 \\
\hline Osfwl1aOFF-2 & Chr2: 1853752-1853774 & CTGAAGGACTTGCACATTTC AGG & LOC_Os02g04230 intron & 4 & 32 & 0 \\
\hline Osfwl1bOFF-1 & Chr6: $17267236-17267258$ & CGGGCAGGACGCCGACATCG CGG & LOC_Os06g29994 CDS & 3 & 32 & 2 \\
\hline Osfwl1bOFF-2 & Chr8: 15832268-15832290 & TGTGCAGGTCGATGACATCA TGG & Intergenic & 3 & 32 & 0 \\
\hline Osfwl2aOFF-1 & Chr1: 14111612-14111634 & GCGATGGTGATGCTCCTCGC CGG & Intergenic & 2 & 32 & 4 \\
\hline Osfwl2aOFF-2 & Chr6: 463763-463785 & ACGCAGGTGAAGCTCCTAAC TGG & LOC_Os06g01800 intron & 4 & 32 & 7 \\
\hline Osfwl2bOFF-1 & Chr4: 24327403-24327425 & CATCTTGGGGAGGTAGAAGA AGG & LOC_Os04g40990 CDS & 3 & 30 & 0 \\
\hline Osfwl2bOFF-2 & Chr2: 22320818-22320840 & CAGCTTGGAGCGGTAGATGC AGG & LOC_Os02g36950 CDS & 3 & 30 & 0 \\
\hline Osfwl3aOFF-1 & Chr4: 23060613-23060635 & ATCGCGGAGATCGTCGACCA GGG & LOC_Os04g38790 CDS & 1 & 27 & 26 \\
\hline Osfwl3aOFF-2 & Chr2: 22312627-22312649 & ATCGCGGAGATCATCGACCG GGG & LOC_Os02g36940 CDS & 1 & 27 & 26 \\
\hline Osfwl3bOFF-2 & Chr2: 4426323-4426345 & GTGGAAGAAGAAGTCGAGGC AGG & LOC_Os02g08330 CDS & 4 & 41 & 0 \\
\hline Osfwl4aOFF-1 & Chr7: 3799011-3799033 & TTTGAAGCAGGTGAAGAGTC CGG & LOC_Os07g07580 intron & 2 & 28 & 23 \\
\hline Osfwl4aOFF-2 & Chr9: 2298486-2298508 & CATGAGGAAGGCGAGGAGTC CGG & LOC_Os09g04339 CDS & 5 & 28 & 0 \\
\hline Osfwl4bOFF-1 & Chr1: 31161078-31161100 & CGCTGCATCTGTCCTCGGGA AGG & Intergenic & 4 & 31 & 0 \\
\hline Osfwl4bOFF-2 & Chr2: 5315090-5315112 & AGCAGAAAGGATCCTGGGGG AGG & Intergenic & 5 & 31 & 0 \\
\hline Osfwl5aOFF-1 & Chr6: 7393721-7393743 & ATCTCAGAAATAATCGACAG CGG & Intergenic & 3 & 31 & 0 \\
\hline Osfwl5aOFF-2 & Chr4: 19176717-19176739 & GTCCCAGGACTCGTCGACAG AGG & LOC_Os04g32020 5’ UTR & 4 & 31 & 0 \\
\hline Osfwl5bOFF-1 & Chr4: 34131133-34131155 & CGCCCGGTGCATCTGCGCGA TGG & LOC_Os04g57330 5' UTR & 3 & 32 & 3 \\
\hline Osfwl5bOFF-2 & Chr6: 22532424-22532446 & ATCACGGTGAGCATGTGCGA TGG & LOC_Os06g38090 intron & 5 & 32 & 0 \\
\hline Osfwl6aOFF-1 & Chr3: 34884082-34884104 & TCGACGTCGTGCGGCACCAG CGG & LOC_Os03g61500 CDS & 1 & 33 & 21 \\
\hline Osfwl6aOFF-2 & Chr3: 16449514-16449536 & AAGACGTCGAGCGGCACCGG CGG & LOC_Os03g28980 CDS & 3 & 33 & 21 \\
\hline Osfwl6bOFF-2 & Chr1: 29494129-29494151 & AGCTAGACGTGCAATCAGTA CGG & Intergenic & 5 & 31 & 0 \\
\hline Osfwl7aOFF-1 & Chr3: 34870990-34871012 & CCCGTGCATCACGTTCGGGA GGG & LOC_Os03g61470 CDS & 1 & 31 & 17 \\
\hline Osfwl7aOFF-2 & Chr10: $21731587-21731609$ & CCCATGCATCACGTTAGGTC CGG & LOC_Os10g40580 5' UTR & 3 & 31 & 0 \\
\hline Osfwl7bOFF-1 & Chr11: 6506399-6506421 & GATCTTGCTCCGGTCGACGC CGG & Intergenic & 3 & 32 & 0 \\
\hline Osfwl7bOFF-2 & Chr2: 22312530-22312552 & CATCTTGGCGCGGTAGAAGC AGG & LOC_Os02g36940 CDS & 3 & 32 & 0 \\
\hline Osfwl8bOFF-1 & Chr3: $34883868-34883890$ & GTTGAGGTCCCATCCGAGCT TGG & LOC_Os03g61500 CDS & 1 & 30 & 30 \\
\hline Osfwl8bOFF-2 & Chr3: 34857174-34857196 & GTTGAGGTGCCACCCAAGCT TGG & LOC_Os03g61430 CDS & 2 & 30 & 13 \\
\hline
\end{tabular}

${ }^{1}$ The PAM sequences are shown in green and the mismatched bases in red. 
Among the putative off-target sites with two mismatches, the mismatched nucleotides of Osfwl6bOFF-1 were separated by only one nucleotide in the PAM-proximal region, and no modifications were detected at this site (Table 3). Genotype analysis of the off-target mutations in $\mathrm{T}_{0}$ plants revealed that $44.9 \%$ and $43.5 \%$ of the genotypes were bi-alleles and heterozygotes, respectively (Figure 1C). Most off-target mutation events were insertions and deletions as observed in the on-target mutation events (Figure 1A,D).

\subsection{Expression Analysis of Cas9 in Transgenic Plants}

The expression level of Cas 9 was examined in transgene-positive plants of several randomly selected $\mathrm{T}_{1}$ lines by qRT-PCR. The Cas 9 mRNA level was approximately $11.6-30.3$ fold that of the OsActin1 gene in different lines (Figure 6).

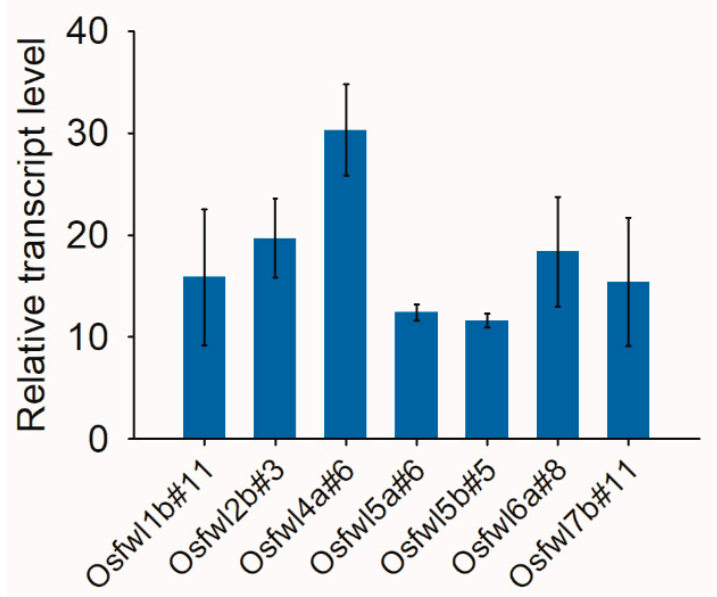

Figure 6. qRT-PCR analysis of Cas 9 expression in the transgene-positive plants of the $\mathrm{T}_{1}$ lines. The rice Actin 1 gene was used as the internal control. Error bars represent standard deviations of three biological repeats.

\section{Discussion}

In this study, rice FWL family genes were mutated using the Agrobacterium-mediated CRISPR/Cas9 system, and the phenotypes of mutants of two genes (OsFWL1 and OsFWL4) were characterized. The results suggest that the OsFWL4 gene is a negative regulator of tiller number and plant yield in rice and that the OsFWL1 gene plays a role in modulating rice grain length.

Rice tiller number is an important agronomic trait that largely affects grain yield. The tiller number of the OsFWL4 gene mutants was increased by up to $45.9 \%$ compared with that of the WT (Figure 2A,B). Additionally, flag leaf width of mutants was also increased (Figure 3A,C). Leaf epidermal cell observation revealed that the increase in leaf width of mutants was caused by an increase in cell number but not in cell size (Figure S4). Hence, OsFWL4 may negatively affect cell proliferation during leaf and tiller development. In the mutants, the grain yield per plant was increased by up to $35.8 \%$ (Figure 2E), suggesting that the OsFWL4 gene may be useful in breeding to improve rice yield.

The grain length of the OsFWL1 gene mutants was significantly higher than that of the WT (Figure 5A,B). Similarly, grain length of the OsFWL3 gene mutant has also been reported to be increased [9]. However, grain width of the OsFWL1 gene mutants was not affected and grain thickness was reduced (Figure 5C,D). The decrease in grain thickness might be caused by insufficient grain filling due to enlarged glumes in the mutants. Finally, grain weight of mutants was not changed. Together, these results suggest that rice $F W L$ genes play a role in the regulation of organ development in rice.

It has been reported that the OsFWL4 gene can enhance Cd resistance when expressed in yeast cells and mediate the translocation of $\mathrm{Cd}$ from the roots to shoots in rice seedlings [15]. Recently, the OsFWL1 gene was also reported to mediate Cd homeostasis in rice [20]. Hence, the two rice 
FWL genes function in both organ development regulation and Cd homeostasis in rice. Similarly, the OsFWL5/PCR1 gene has been found to confer Cd resistance and $\mathrm{Zn}$ hypersensitivity upon expression in yeast and to modulate grain size and weight and metal ion homeostasis in rice $[13,14]$. However, how a single $F W L$ gene fulfills such diverse roles remains unknown. Interestingly, the OsFWL5/PCR1 protein has been found to be localized as oligomers in the plasma membrane microdomains [13]. Additionally, GmFWL1, an important FWL protein involved in soybean nodulation, has also been demonstrated to be a plasma membrane microdomain-associated protein $[5,10]$. The plasma membrane microdomains are membrane sub-compartments consisting of special lipids and proteins and are considered signal integration hubs of cells [35]. Hence, the membrane microdomain-associated FWL protein may act in several distinct signaling pathways and thus affect multiple biological processes in plants. Both OsFWL1 and OsFWL4 proteins are located in the plasma membrane, and the OsFWL4 protein is distributed in a punctate manner $[9,15]$. We speculate that OsFWL4 may also be a microdomain-associated protein. A gene co-expression analysis revealed that OsFWL4 may be involved in many cell functions (Tables S7 and S8). The OsFWL1 gene is reported to be co-expressed with the zinc finger and ubiquitination-related protein genes [9].

CRISPR/Cas9 DNA can be delivered into rice cells by Agrobacterium-mediated transformation and integrated into the rice genome. Studies have shown that T-DNA truncation frequently occurs in Agrobacterium-mediated transformation [36,37]. Detection of CRISPR/Cas9 DNA in unmutated $\mathrm{T}_{0}$ plants revealed that most ( 25 out of 39 , excluding two plants that escaped hygromycin selection) of them lacked sgRNA and/or Cas 9 transgenes (Table S2). This indicates that the integrity of the sgRNA/Cas9 expression cassette is an important factor affecting editing efficiency. Truncation of T-DNA can occur at its different ends (left, right, or both ends) and different stages of integration (before or during integration) [36-39]. In rice, truncated T-DNAs were detected in more than $18 \%$ of the transformants [40]. Hence, improving the quality of T-DNA integration may aid in further increasing the efficiency of CRISPR/Cas9 gene editing based on Agrobacterium-mediated transformation.

T-DNA segregation analysis revealed that transgene-free plants could be obtained in several $\mathrm{T}_{1}$ plants for all lines examined (Figure S2). This suggests that T-DNA insertions in CRISPR/Cas9 gene-edited plants can be easily eliminated in the $\mathrm{T}_{1}$ generation. Interestingly, inconsistent segregation of HPT, sgRNA, and Cas9 transgenes was observed in two lines (Osfwl3a\#4 and Osfwl4b\#6; Figure S2). The absence of sgRNA and Cas 9 transgenes in Osfwl $4 \mathrm{~b} \# 6 \mathrm{~T}_{1}$ plants was caused by the lack of these sequences in the $\mathrm{T}_{0}$ plant. In the $20 \mathrm{~T}_{1}$ plants examined for line Osfwl3a\#4, seven plants contained only the sgRNA transgene, 12 plants contained all the three transgenes, and one plant had no transgene (Figures S2 and S3). This inconsistent segregation could be attributed to the presence of two T-DNA insertion sites in this line; one contained the complete T-DNA fragment, whereas the other harbored a truncated T-DNA with only the sgRNA transgene.

The off-target effect is a major concern in the application of CRISPR/Cas9 technology. Several studies have reported that the CRISPR/Cas9 system is highly specific in plants [27,32,41,42]. However, moderate or even high-frequency off-target mutagenesis has also been reported [43-46]. In the present study, potential editing events at 30 putative off-targets of the 15 sgRNAs were examined. We detected mutations in 13 out of the 30 putative off-target sites (Table 3). Analysis of the relationship between mismatch numbers of target-like sequences and off-target activity revealed that all the sequences harboring single mismatches with the sgRNAs and $80.0 \%$ of the sequences containing double mismatches were cleaved. These results indicate that at least two mismatches between the sgRNA and potential off-target sequences are required to minimize the off-target effects. Interestingly, an off-target site with up to four mismatches (Osfwl2aOFF-2) was also mutated (Table 3). The first mismatch of this site located at the first base in the $5^{\prime}$ end is usually tolerated by CRISPR/Cas9. Additionally, all four mismatched bases of this site were adenine (Table 3), which led to $\mathrm{rN}$ :dT base pairing during sgRNA binding. Generally, the rN:dT mismatches are well tolerated $[47,48]$. Hence, both the identity and position of mismatched bases might contribute to the cleavage of this site by Cas9. The results suggest that the sgRNAs should be designed carefully to minimize or avoid off-target mutagenesis in plants. 


\section{Materials and Methods}

\subsection{Plant Materials and Growth Conditions}

The rice variety used for transformation was Zhonghua 11 (Oryza sativa L. ssp. japonica). The rice plants were grown in experimental fields of the Huaiyin Normal University in Huai'an, China or in Lingshui, China in different growing seasons. Rice plants were also grown in plastic buckets in growth chambers with a $14 / 10 \mathrm{~h}$ light/dark cycle at 30 and $25^{\circ} \mathrm{C}$.

\subsection{Construction of the CRISPR/Cas9 Plasmids}

Maize ubiquitin promoter was used to drive the expression of the $h S p C a s 9$ gene, which was amplified from the pX260 vector [49]. The construct was inserted into the pCAMBIA1300 vector (Cambia, Canberra, Australia) harboring the hygromycin resistance gene. The BsaI site originally present in the pCAMBIA1300 vector was disrupted by point mutation. Subsequently, a construct containing the OsU6 promoter [50], a negative selection marker gene $(c c d B)$ with BsaI sites at both ends, and a fragment encoding the sgRNA scaffold derived from the pX260 vector was cloned into this vector to generate the CRISPR/Cas9 binary vector (Figure S1). Target sequences containing at least one mismatch in the 12-bp PAM proximal region with other genomic sites and relatively high GC content were selected for the rice FWL genes. The designed target sequences were synthesized, annealed, and ligated into the $B s a$ I site of the CRISPR/Cas9 binary vector to obtain the CRISPR plasmids for targeted gene editing. The plasmids were propagated in Escherichia coli competent cells and subsequently introduced into the Agrobacterium tumefaciens strain EHA105 for Agrobacterium-mediated transformation of rice [51].

\subsection{Detection of On-Target and Off-Target Mutations}

The potential off-targets of sgRNAs were predicted using the "offTarget" program in the CRISPR-GE software toolkit [52]. Genomic DNA of rice was extracted using the CTAB (cetyl trimethylammonium bromide) method. The DNA fragments covering the on-target and off-target sites were amplified by PCR using the specific genomic primers. PCR amplifications were performed in a Mastercycler nexus gradient thermal cycler (Eppendorf, Hamburg, Germany). Each reaction contained DNA templates, $1 \times$ PCR buffer, $0.4 \mathrm{mmol} \mathrm{L}^{-1} \mathrm{dNTPs}$ (deoxynucleotide triphosphates), $0.3 \mu \mathrm{mol} \mathrm{L}^{-1}$ of both forward and reverse primers, and 1 U KOD FX DNA polymerase (Toyobo, Osaka, Japan). Distilled water was added to a final volume of $50 \mu \mathrm{L}$. The PCR conditions included an initial incubation at $94^{\circ} \mathrm{C}$ for $2 \mathrm{~min}$, followed by 30 cycles of $98{ }^{\circ} \mathrm{C}$ for $10 \mathrm{~s}, 50-55^{\circ} \mathrm{C}$ for $30 \mathrm{~s}$, and $68^{\circ} \mathrm{C}$ for $0.5-1 \mathrm{~min}$, with a final extension at $68^{\circ} \mathrm{C}$ for $5 \mathrm{~min}$. The amplified products were sequenced directly. For some samples, PCR products were cloned and individual clones were sequenced. The superimposed sequencing chromatograms of heterozygous and bi-allelic mutations were decoded using DSDecodeM [53]. The PCR primers used are listed in Table S9.

\subsection{Detection of the T-DNA Fragment}

The T-DNA fragment in transgenic plants was detected by PCR using three pairs of primers amplifying the HPT, sgRNA, and Cas 9 transgenes. Amplifications were carried out in a Mastercycler nexus gradient thermal cycler (Eppendorf, Hamburg, Germany). Each reaction contained DNA

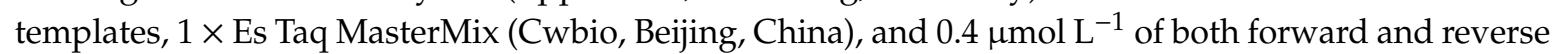
primers. Distilled water was added to a final volume of $25 \mu \mathrm{L}$. The PCR conditions included an initial incubation at $94{ }^{\circ} \mathrm{C}$ for $2 \mathrm{~min}$, followed by 30 cycles of $94{ }^{\circ} \mathrm{C}$ for $30 \mathrm{~s}, 55^{\circ} \mathrm{C}$ for $30 \mathrm{~s}$, and $72{ }^{\circ} \mathrm{C}$ for $30 \mathrm{~s}$, with a final extension at $72{ }^{\circ} \mathrm{C}$ for $2 \mathrm{~min}$. PCR products were separated by electrophoresis on $1.5 \%$ agarose gels containing GoldView I nucleic acid dye (Solarbio, Beijing, China). The primers used are listed in Table S9. 


\subsection{RNA Isolation and $q R T-P C R$}

RNA isolation and qRT-PCR analysis were performed as previously described [54]. Briefly, total RNA was isolated using the TRIzol Total RNA Isolation kit (Sangon Biotech, Shanghai, China) and treated with DNase I (Sangon Biotech, Shanghai, China). Eight hundred nanograms of total RNA was reverse-transcribed using RevertAid Premium Reverse Transcriptase (Thermo Fisher Scientific, Waltham, MA, USA) and diluted ten-fold for PCR amplification. The PCR was performed on a LightCycler480 II instrument (Roche, Basel, Switzerland). Each reaction contained $2 \mu \mathrm{L}$ of cDNA template, $10 \mu \mathrm{L}$ of SYBR Green qPCR Master Mix (BBI, Toronto, ON, Canada), and $0.2 \mu \mathrm{mol} \mathrm{L}{ }^{-1}$ gene-specific primers in a final volume of $20 \mu \mathrm{L}$. The PCR conditions included an initial incubation at $95^{\circ} \mathrm{C}$ for $3 \mathrm{~min}$, followed by 45 cycles of $95^{\circ} \mathrm{C}$ for $5 \mathrm{~s}$ and $60^{\circ} \mathrm{C}$ for $30 \mathrm{~s}$. The specificity of the PCR reactions was determined by melting curve analyses of the products. Relative expression levels were calculated by the $2^{-\triangle \Delta C T}$ method. The rice Actin 1 gene was used as the internal control. The primer sequences are listed in Table S9.

\subsection{Leaf Epidermal Cell Observation}

Epidermal cells in flag leaves were observed following the method used by Yoshikawa et al. [55].

\subsection{Trait Measurement}

Plant height, leaf size, and tiller number of WT and mutants were measured in the field at the maturity stage. For tiller number determination, only seed setting tillers were counted. Rice plants were harvested when the grains were fully mature. Grains threshed from each plant were dried, and filled grains were weighed to determine grain yield per plant. Fully filled grains were used for determining grain size and weight. Grain weight was measured based on 100 grains and converted to 1000-grain weight.

\section{Conclusions}

Collectively, our findings showed that transgene-free rice plants with targeted mutations can be produced in the $\mathrm{T}_{1}$ generation using the Agrobacterium-mediated CRISPR/Cas9 system, and that the OsFWL4 gene plays a role in the regulation of tillering and plant yield in rice. The specific mutants obtained in this study provide valuable materials for functional analysis of rice $F W L$ genes.

Supplementary Materials: Supplementary materials can be found at http://www.mdpi.com/1422-0067/21/3/809/s1.

Author Contributions: C.Y. and X.Z. designed the study; Q.G., G.L., H.S., M.X., H.W., J.J., and D.W. performed the experiments; Q.G. and G.L. analyzed the data; and Q.G. and X.Z. wrote the manuscript. All authors have read and agreed to the published version of the manuscript.

Funding: This research was funded by the National Key Research Program of China (2017YFD0100400), the National Natural Science Foundation of China (31601385), the National Science and Technology Major Project (2016ZX08012-002), and the Natural Science Foundation of Jiangsu Province (BK20160429 and BK20180107).

Acknowledgments: We thank Yangwen Qian from the Biogle Genome Editing Center (Changzhou) for assistance with gene transformation. We also thank the anonymous reviewers for their constructive comments and suggestions.

Conflicts of Interest: The authors declare no conflict of interest. The funders had no role in the design of the study; in the collection, analyses, or interpretation of data; in the writing of the manuscript, or in the decision to publish the results.

\section{References}

1. Cong, B.; Liu, J.P.; Tanksley, S.D. Natural alleles at a tomato fruit size quantitative trait locus differ by heterochronic regulatory mutations. Proc. Natl. Acad. Sci. USA 2002, 99, 13606-13611. [CrossRef]

2. Frary, A.; Nesbitt, T.C.; Grandillo, S.; Knaap, E.; Cong, B.; Liu, J.; Meller, J.; Elber, R.; Alpert, K.B.; Tanksley, S.D. fw2.2: A quantitative trait locus key to the evolution of tomato fruit size. Science 2000, 289, 85-88. [CrossRef] 
3. Liu, J.; Cong, B.; Tanksley, S.D. Generation and analysis of an artificial gene dosage series in tomato to study the mechanisms by which the cloned quantitative trait locus fw2.2 controls fruit size. Plant Physiol. 2003, 132, 292-299. [CrossRef]

4. Guo, M.; Rupe, M.A.; Dieter, J.A.; Zou, J.; Spielbauer, D.; Duncan, K.E.; Howard, R.J.; Hou, Z.; Simmons, C.R. Cell Number Regulator1 affects plant and organ size in maize: Implications for crop yield enhancement and heterosis. Plant Cell 2010, 22, 1057-1073. [CrossRef]

5. Libault, M.; Zhang, X.C.; Govindarajulu, M.; Qiu, J.; Ong, Y.T.; Brechenmacher, L.; Berg, R.H.; Hurley-Sommer, A.; Taylor, C.G.; Stacey, G. A member of the highly conserved FWL (tomato FW2.2-like) gene family is essential for soybean nodule organogenesis. Plant J. 2010, 62, 852-864. [CrossRef] [PubMed]

6. Dahan, Y.; Rosenfeld, R.; Zadiranov, V.; Irihimovitch, V. A proposed conserved role for an avocado FW2.2-like gene as a negative regulator of fruit cell division. Planta 2010, 232, 663-676. [CrossRef] [PubMed]

7. De Franceschi, P.; Stegmeir, T.; Cabrera, A.; van der Knaap, E.; Rosyara, U.R.; Sebolt, A.M.; Dondini, L.; Dirlewanger, E.; Quero-Garcia, J.; Campoy, J.A.; et al. Cell number regulator genes in Prunus provide candidate genes for the control of fruit size in sweet and sour cherry. Mol. Breeding 2013, 32, 311-326. [CrossRef] [PubMed]

8. Li, Z.; He, C. Physalis floridana Cell Number Regulator1 encodes a cell membrane-anchored modulator of cell cycle and negatively controls fruit size. J. Exp. Bot. 2015, 66, 257-270. [CrossRef] [PubMed]

9. Xu, J.; Xiong, W.T.; Cao, B.B.; Yan, T.Z.; Luo, T.; Fan, T.T.; Luo, M.Z. Molecular characterization and functional analysis of "fruit-weight 2.2-like" gene family in rice. Planta 2013, 238, 643-655. [CrossRef]

10. Qiao, Z.; Brechenmacher, L.; Smith, B.; Strout, G.W.; Mangin, W.; Taylor, C.; Russell, S.D.; Stacey, G.; Libault, M. The GmFWL1 (FW2-2-like) nodulation gene encodes a plasma membrane microdomain-associated protein. Plant Cell Environ. 2017, 40, 1442-1455. [CrossRef]

11. Qiao, K.; Tian, Y.; Hu, Z.; Chai, T. Wheat Cell Number Regulator CNR10 enhances the tolerance, translocation, and accumulation of heavy metals in plants. Environ. Sci. Technol. 2019, 53, 860-867. [CrossRef] [PubMed]

12. Song, W.Y.; Choi, K.S.; Kim, D.Y.; Geisler, M.; Park, J.; Vincenzetti, V.; Schellenberg, M.; Kim, S.H.; Lim, Y.P.; Noh, E.W.; et al. Arabidopsis PCR2 is a zinc exporter involved in both zinc extrusion and long-distance zinc transport. Plant Cell 2010, 22, 2237-2252. [CrossRef] [PubMed]

13. Song, W.Y.; Lee, H.S.; Jin, S.R.; Ko, D.; Martinoia, E.; Lee, Y.; An, G.; Ahn, S.N. Rice PCR1 influences grain weight and Zn accumulation in grains. Plant Cell Environ. 2015, 38, 2327-2339. [CrossRef] [PubMed]

14. Song, W.Y.; Martinoia, E.; Lee, J.; Kim, D.; Kim, D.Y.; Vogt, E.; Shim, D.; Choi, K.S.; Hwang, I.; Lee, Y. A novel family of cys-rich membrane proteins mediates cadmium resistance in Arabidopsis. Plant Physiol. 2004, 135, 1027-1039. [CrossRef]

15. Xiong, W.T.; Wang, P.; Yan, T.Z.; Cao, B.B.; Xu, J.; Liu, D.F.; Luo, M.Z. The rice "fruit-weight 2.2-like" gene family member OsFWL4 is involved in the translocation of cadmium from roots to shoots. Planta 2018, 247, 1247-1260. [CrossRef]

16. Kurusu, T.; Nishikawa, D.; Yamazaki, Y.; Gotoh, M.; Nakano, M.; Hamada, H.; Yamanaka, T.; Iida, K.; Nakagawa, Y.; Saji, H.; et al. Plasma membrane protein OsMCA1 is involved in regulation of hypo-osmotic shock-induced $\mathrm{Ca}^{2+}$ influx and modulates generation of reactive oxygen species in cultured rice cells. BMC Plant Biol. 2012, 12, 11. [CrossRef]

17. Nakagawa, Y.; Katagiri, T.; Shinozaki, K.; Qi, Z.; Tatsumi, H.; Furuichi, T.; Kishigami, A.; Sokabe, M.; Kojima, I.; Sato, S.; et al. Arabidopsis plasma membrane protein crucial for $\mathrm{Ca}^{2+}$ influx and touch sensing in roots. Proc. Natl. Acad. Sci. USA 2007, 104, 3639-3644. [CrossRef]

18. Song, W.Y.; Choi, K.S.; Alexis de, A.; Martinoia, E.; Lee, Y. Brassica juncea plant cadmium resistance 1 protein (BjPCR1) facilitates the radial transport of calcium in the root. Proc. Natl. Acad. Sci. USA 2011, 108, 19808-19813. [CrossRef]

19. Yamanaka, T.; Nakagawa, Y.; Mori, K.; Nakano, M.; Imamura, T.; Kataoka, H.; Terashima, A.; Iida, K.; Kojima, I.; Katagiri, T.; et al. MCA1 and MCA2 that mediate $\mathrm{Ca}^{2+}$ uptake have distinct and overlapping roles in Arabidopsis. Plant Physiol. 2010, 152, 1284-1296. [CrossRef]

20. Wang, F.; Tan, H.; Han, J.; Zhang, Y.; He, X.; Ding, Y.; Chen, Z.; Zhu, C. A novel family of PLAC8 motif-containing/PCR genes mediates $\mathrm{Cd}$ tolerance and $\mathrm{Cd}$ accumulation in rice. Environ. Sci. Eur. 2019, 31, 82. [CrossRef]

21. Scully, R.; Panday, A.; Elango, R.; Willis, N.A. DNA double-strand break repair-pathway choice in somatic mammalian cells. Nat. Rev. Mol. Cell Biol. 2019, 20, 698-714. [CrossRef] [PubMed] 
22. Chen, K.L.; Wang, Y.P.; Zhang, R.; Zhang, H.W.; Gao, C.X. CRISPR/Cas genome editing and precision plant breeding in agriculture. Annu. Rev. Plant Biol. 2019, 70, 667-697. [CrossRef] [PubMed]

23. Jinek, M.; Chylinski, K.; Fonfara, I.; Hauer, M.; Doudna, J.A.; Charpentier, E. A programmable dual-RNA-guided DNA endonuclease in adaptive bacterial immunity. Science 2012, 337, 816-821. [CrossRef] [PubMed]

24. Sternberg, S.H.; Redding, S.; Jinek, M.; Greene, E.C.; Doudna, J.A. DNA interrogation by the CRISPR RNA-guided endonuclease Cas9. Nature 2014, 507, 62-67. [CrossRef]

25. Feng, C.; Su, H.D.; Bai, H.; Wang, R.; Liu, Y.L.; Guo, X.R.; Liu, C.; Zhang, J.; Yuan, J.; Birchler, J.A.; et al. High-efficiency genome editing using a $d m c 1$ promoter-controlled CRISPR/Cas9 system in maize. Plant Biotechnol. J. 2018, 16, 1848-1857. [CrossRef]

26. Wang, Z.P.; Xing, H.L.; Dong, L.; Zhang, H.Y.; Han, C.Y.; Wang, X.C.; Chen, Q.J. Egg cell-specific promoter-controlled CRISPR/Cas9 efficiently generates homozygous mutants for multiple target genes in Arabidopsis in a single generation. Genome Biol. 2015, 16, 144. [CrossRef]

27. Zhang, H.; Zhang, J.; Wei, P.; Zhang, B.; Gou, F.; Feng, Z.; Mao, Y.; Yang, L.; Xu, N.; Zhu, J.K. The CRISPR/Cas9 system produces specific and homozygous targeted gene editing in rice in one generation. Plant Biotechnol. J. 2014, 12, 797-807. [CrossRef]

28. Zhou, H.; Liu, B.; Weeks, D.P.; Spalding, M.H.; Yang, B. Large chromosomal deletions and heritable small genetic changes induced by CRISPR/Cas9 in rice. Nucleic Acids Res. 2014, 42, 10903-10914. [CrossRef]

29. Ma, X.; Zhang, Q.; Zhu, Q.; Liu, W.; Chen, Y.; Qiu, R.; Wang, B.; Yang, Z.; Li, H.; Lin, Y.; et al. A robust CRISPR/Cas9 system for convenient, high-efficiency multiplex genome editing in monocot and dicot plants. Mol. Plant 2015, 8, 1274-1284. [CrossRef]

30. Chari, R.; Yeo, N.C.; Chavez, A.; Church, G.M. sgRNA Scorer 2.0: A species-independent model to predict CRISPR/Cas9 activity. ACS Synth. Biol. 2017, 6, 902-904. [CrossRef]

31. Mao, Y.; Botella, J.R.; Zhu, J.K. Heritability of targeted gene modifications induced by plant-optimized CRISPR systems. Cell Mol. Life Sci. 2017, 74, 1075-1093. [CrossRef] [PubMed]

32. Xu, R.F.; Li, H.; Qin, R.Y.; Li, J.; Qiu, C.H.; Yang, Y.C.; Ma, H.; Li, L.; Wei, P.C.; Yang, J.B. Generation of inheritable and "transgene clean" targeted genome-modified rice in later generations using the CRISPR/Cas9 system. Sci. Rep. 2015, 5, 11491. [CrossRef] [PubMed]

33. Hruz, T.; Laule, O.; Szabo, G.; Wessendorp, F.; Bleuler, S.; Oertle, L.; Widmayer, P.; Gruissem, W.; Zimmermann, P. Genevestigator v3: A reference expression database for the meta-analysis of transcriptomes. Adv. Bioinform. 2008, 2008, 420747. [CrossRef] [PubMed]

34. Gingerich, D.J.; Hanada, K.; Shiu, S.H.; Vierstra, R.D. Large-scale, lineage-specific expansion of a bric-a-brac/tramtrack/broad complex ubiquitin-ligase gene family in rice. Plant Cell 2007, 19, 2329-2348. [CrossRef] [PubMed]

35. Yu, M.; Cui, Y.; Zhang, X.; Li, R.; Lin, J. Organization and dynamics of functional plant membrane microdomains. Cell Mol. Life Sci. 2019. [CrossRef] [PubMed]

36. Gheysen, G.; Herman, L.; Breyne, P.; Gielen, J.; Van Montagu, M.; Depicker, A. Cloning and sequence analysis of truncated T-DNA inserts from Nicotiana tabacum. Gene 1990, 94, 155-163. [CrossRef]

37. Herman, L.; Jacobs, A.; Van Montagu, M.; Depicker, A. Plant chromosome/marker gene fusion assay for study of normal and truncated T-DNA integration events. Mol. Gen. Genet. 1990, 224, 248-256. [CrossRef]

38. Gheysen, G.; Villarroel, R.; Van Montagu, M. Illegitimate recombination in plants: A model for T-DNA integration. Genes Dev. 1991, 5, 287-297. [CrossRef]

39. Kim, S.R.; Lee, J.; Jun, S.H.; Park, S.; Kang, H.G.; Kwon, S.; An, G. Transgene structures in T-DNA-inserted rice plants. Plant Mol. Biol. 2003, 52, 761-773. [CrossRef]

40. Yin, Z.; Wang, G.L. Evidence of multiple complex patterns of T-DNA integration into the rice genome. Theor. Appl. Genet. 2000, 100, 461-470. [CrossRef]

41. Feng, Z.; Mao, Y.; Xu, N.; Zhang, B.; Wei, P.; Yang, D.L.; Wang, Z.; Zhang, Z.; Zheng, R.; Yang, L.; et al. Multigeneration analysis reveals the inheritance, specificity, and patterns of CRISPR/Cas-induced gene modifications in Arabidopsis. Proc. Natl. Acad. Sci. USA 2014, 111, 4632-4637. [CrossRef] [PubMed]

42. Tang, X.; Liu, G.Q.; Zhou, J.P.; Ren, Q.R.; You, Q.; Tian, L.; Xin, X.H.; Zhong, Z.H.; Liu, B.L.; Zheng, X.L.; et al. A large-scale whole-genome sequencing analysis reveals highly specific genome editing by both Cas9 and Cpf1 (Cas12a) nucleases in rice. Genome Biol. 2018, 19, 84. [CrossRef] [PubMed] 
43. Endo, M.; Mikami, M.; Toki, S. Multigene knockout utilizing off-target mutations of the CRISPR/Cas9 system in rice. Plant Cell Physiol. 2015, 56, 41-47. [CrossRef] [PubMed]

44. Lawrenson, T.; Shorinola, O.; Stacey, N.; Li, C.; Ostergaard, L.; Patron, N.; Uauy, C.; Harwood, W. Induction of targeted, heritable mutations in barley and Brassica oleracea using RNA-guided Cas9 nuclease. Genome Biol. 2015, 16, 258. [CrossRef]

45. Li, M.R.; Li, X.X.; Zhou, Z.J.; Wu, P.Z.; Fang, M.C.; Pan, X.P.; Lin, Q.P.; Luo, W.B.; Wu, G.J.; Li, H.Q. Reassessment of the four yield-related genes Gn1a, DEP1, GS3, and IPA1 in rice using a CRISPR/Cas9 system. Front. Plant Sci. 2016, 7, 377. [CrossRef]

46. Zhang, Q.; Xing, H.L.; Wang, Z.P.; Zhang, H.Y.; Yang, F.; Wang, X.C.; Chen, Q.J. Potential high-frequency off-target mutagenesis induced by CRISPR/Cas9 in Arabidopsis and its prevention. Plant Mol. Biol. 2018, 96, 445-456. [CrossRef]

47. Doench, J.G.; Fusi, N.; Sullender, M.; Hegde, M.; Vaimberg, E.W.; Donovan, K.F.; Smith, I.; Tothova, Z.; Wilen, C.; Orchard, R.; et al. Optimized sgRNA design to maximize activity and minimize off-target effects of CRISPR-Cas9. Nat. Biotechnol. 2016, 34, 184-191. [CrossRef]

48. Hsu, P.D.; Scott, D.A.; Weinstein, J.A.; Ran, F.A.; Konermann, S.; Agarwala, V.; Li, Y.; Fine, E.J.; Wu, X.; Shalem, O.; et al. DNA targeting specificity of RNA-guided Cas9 nucleases. Nat. Biotechnol. 2013, 31, 827-832. [CrossRef]

49. Cong, L.; Ran, F.A.; Cox, D.; Lin, S.; Barretto, R.; Habib, N.; Hsu, P.D.; Wu, X.; Jiang, W.; Marraffini, L.A.; et al. Multiplex genome engineering using CRISPR/Cas systems. Science 2013, 339, 819-823. [CrossRef]

50. Feng, Z.; Zhang, B.; Ding, W.; Liu, X.; Yang, D.L.; Wei, P.; Cao, F.; Zhu, S.; Zhang, F.; Mao, Y.; et al. Efficient genome editing in plants using a CRISPR/Cas system. Cell Res. 2013, 23, 1229-1232. [CrossRef]

51. Nishimura, A.; Aichi, I.; Matsuoka, M. A protocol for Agrobacterium-mediated transformation in rice. Nat. Protoc. 2006, 1, 2796-2802. [CrossRef] [PubMed]

52. Xie, X.; Ma, X.; Zhu, Q.; Zeng, D.; Li, G.; Liu, Y.G. CRISPR-GE: A convenient software toolkit for CRISPR-based genome editing. Mol. Plant 2017, 10, 1246-1249. [CrossRef] [PubMed]

53. Liu, W.; Xie, X.; Ma, X.; Li, J.; Chen, J.; Liu, Y.G. DSDecode: A web-based tool for decoding of sequencing chromatograms for genotyping of targeted mutations. Mol. Plant 2015, 8, 1431-1433. [CrossRef] [PubMed]

54. Gao, Q.S.; Xu, S.H.; Zhu, X.Y.; Wang, L.L.; Yang, Z.F.; Zhao, X.X. Genome-wide identification and characterization of the RIO atypical kinase family in plants. Genes Genom. 2018, 40, 669-683. [CrossRef] [PubMed]

55. Yoshikawa, T.; Eiguchi, M.; Hibara, K.; Ito, J.; Nagato, Y. Rice slender leaf 1 gene encodes cellulose synthase-like D4 and is specifically expressed in M-phase cells to regulate cell proliferation. J. Exp. Bot. 2013, 64, 2049-2061. [CrossRef] [PubMed]

(C) 2020 by the authors. Licensee MDPI, Basel, Switzerland. This article is an open access article distributed under the terms and conditions of the Creative Commons Attribution (CC BY) license (http://creativecommons.org/licenses/by/4.0/). 